\title{
A SYSTEMATIC REVIEW OF RESEARCH ON TACTICAL PERIODIZATION: ABSENCE OF EMPIRICAL DATA, BURDEN OF PROOF, AND BENEFIT OF DOUBT
}

review paper

( ) University School of Physical Education in Wroclaw

DOI: https://doi.org/10.5114/hm.2020.95329

\author{
JOSÉ AFONSO ${ }^{1}$, CRISTIANA BESSA ${ }^{1}$, PANTELIS T. NIKOLAIDIS ${ }^{2}$, ISRAEL TEOLDO ${ }^{3}$, \\ FILIPE MANUEL CLEMENTE ${ }^{4,5}$ \\ ${ }^{1}$ Centre for Research, Education, Innovation and Intervention in Sport, Faculty of Sport, University of Porto, Porto, Portugal \\ ${ }^{2}$ Exercise Physiology Laboratory, Nikaia, Greece \\ ${ }^{3}$ Centre of Research and Studies in Soccer, Federal University of Viçosa, Viçosa, Brazil \\ ${ }^{4}$ Escola Superior Desporto e Lazer, Instituto Politécnico de Viana do Castelo, Viana do Castelo, Portugal \\ ${ }^{5}$ Instituto de Telecomunicações, Delegação da Covilhã, Covilhã, Portugal
}

\begin{abstract}
Purpose. Tactical Periodization was developed as an alternative paradigm to periodization. The principles established by its proponents seem theoretically reasonable and well adjusted to competitive sports, especially team sports with year-long competitions, and are quickly becoming popular in sports such as soccer, rugby, and tennis. There are valid arguments in favour of Tactical Periodization, but in science the burden of proof falls on the shoulders of the proponents. Therefore, the aim of this paper was to systematically review articles focusing on Tactical Periodization published in peer-reviewed journals. Methods. The research involved original experimental articles assessing Tactical Periodization in any sport, published in English or Portuguese.

Results. Although Tactical Periodization is an interesting theoretical concept and is currently popular, no empirical research on the subject was found. For that reason, it is premature to scientifically support this periodization model.

Conclusions. The benefit of doubt can be temporarily conceded but Tactical Periodization was created more than 20 years ago. Therefore, it must be properly tested if it aims to be an alternative to current periodized models.
\end{abstract}

Key words: Tactical Periodization, scientific research, burden of proof, football, soccer, sports training

\section{Introduction}

Tactical Periodization is a holistic training approach to planning that has gained increased attention in team sports [1, 2]. Its proponent, Vítor Frade (Portuguese), developed the concept more than a decade ago [3]; more recently, the concept achieved considerable traction, especially owing to the competitive success of some Portuguese soccer coaches that passionately defend it (e.g., José Mourinho, Leonardo Jardim, André VillasBoas). Tactical Periodization has been applied in soccer (from young ages to adult teams), but also expanded to other sports, such as rugby [2,4] and tennis [5]. On April 26, 2017, Tactical Periodization was presented in The New York Times as an extended interview with the creator of the concept [6]. In sum, the model is increasingly popular and is being considered as an alternative approach to planning and periodizing.

Tactical Periodization presents a very interesting rationale and key points, which will be developed in this manuscript. However, the creator of the concept has never written an article or book defining the idea or explaining how to apply it, and so it was left to others to systematize the principles behind this approach, using interviews and analysis of content as methodology. Although these methodological approaches constitute second-hand accounts, they have not been detracted, and so this manuscript will abide by what is written. The most concise, objective, and reliable definitions are those published in peer-review journals.

Correspondence address: Filipe Manuel Clemente, Complexo Desportivo e Lazer de Melgaço - Monte de Prado, 4960-320,

Melgaço, Portugal, e-mail: filipe.clemente5@gmail.com

Received: November 19, 2019

Accepted for publication: May 12, 2020

Citation: Afonso J, Bessa C, Nikolaidis PT, Teoldo I, Clemente FM. A systematic review of research on Tactical Periodization: absence of empirical data, burden of proof, and benefit of doubt Hum Mov. 2020;21(4):37-43; doi: https://doi.org/10.5114/ hm.2020.95329. 
J. Afonso, C. Bessa, P.T. Nikolaidis, I. Teoldo, F.M. Clemente, Tactical Periodization: a review

Indeed, authors such as Crespo [5] and Robertson and Joyce [4] have systematically and objectively defined these concepts. They define Tactical Periodization as a form of periodization that considers all training factors (i.e., tactical, physical, psychological, and technical) and treats tactics as a 'supra-dimension,' i.e., all training factors emerge from, and contribute to, tactical performance. Notwithstanding, the training factors may also change the tactical approach, and Tactical Periodization recognizes the need for these bidirectional, systemic relationships [1].

Therefore, Tactical Periodization represents a major departure from other existing periodized models, usually focusing almost exclusively on the more "physical' aspects of performance or, when concentrating on other training factors, usually relating to one factor at a time (see review by Afonso et al. [7]). In Tactical Periodization, the word 'tactical' refers not only to the traditional tactical concept (e.g., team organization), but also to a wider concept that understands the game as a functional whole. In this context, Tactical Periodization considers all training factors, i.e., tactical, technical, psychosocial, and physical. Incidentally, it should be noted that how the term 'physical' is used in sports is actually quite reductionist, since all human actions are physical and therefore it is surprising how the so-called 'physical' factor of training is usually considered separately from tactical, technical, and psychological aspects. Consequently, it is important to again highlight that Tactical Periodization is not simply a periodization of the tactical aspects, and this will be relevant when search criteria are defined.

At the core of Tactical Periodization is the concept of game model, a dynamic and evolving framework which informs all the training process [1]. Tactical Periodization is then organized around 3 main methodologic principles: (i) the principle of propensions (create open situations but where the key scenarios emerge frequently); (ii) the principle of complex progression (which considers learning as a nonlinear process and proposes that a certain degree of complexity should always present); and (iii) the principle of horizontal alternation in specificity (the game problems are always at the core of the stimuli, but their specific focus changes to alternate load and recovery) [8]. These principles are used to design the morphocycle [1, 8], which roughly corresponds to the training week (microcycle), and focus deeply on preparing the team for playing the next challenge on the basis of the principles and model of play. The focus on the morphocycle allows consideration for what happened before and makes predictions only in the short-term, something that has been suggested for the paradigm of periodization as a whole as well [9], and thus represents a major departure from almost all other periodized models. Despite this short-term adjusting process, the main concept of this periodization related with the stabilization of the physical stimulus across the week and between weeks, namely maintaining the same horizontal distribution of the load across the week, aiming to respect a principle of stabilization [10]. Additionally, when designing a morphocycle, every training factor and even factors outside of training (e.g., travel schedules, time zones, psychological effect of the next opponent ranking) are considered [4, 11].

Thus, the principles underlying Tactical Periodization seem theoretically reasonable and provide an interesting alternative to the most common approaches to periodization. Furthermore, Tactical Periodization acknowledges that any training plan should include all the training factors, and not only the more traditionally called 'physical aspects' of performance, which clearly dominate research on exercise periodization, as it was demonstrated in a recent comprehensive review [7]. However, popularity and support of elite-level coaches do not make a concept immune to critique and do not dismiss the need for proper scientific research to evaluate it more objectively. The concept and principles emphasized by Tactical Periodization should be scrutinized in a scientific manner. Indeed, Buchheit et al. [11] clearly state that despite the growing interest in such a seductive approach, it is still not known how players really respond to such load management strategies.

It can be contended that all novel approaches should be given the benefit of the doubt, especially when their rationale is solid, as is the case of Tactical Periodization. Still, Tactical Periodization is not exactly a novel concept, having at least a 20-year history. Therefore, as in all scientific endeavours, the burden of proof falls on the shoulders of the proponents $[12,13]$. Otherwise, mere opinions or - worse - pseudoscience can disguise as scientifically validated concepts. To become a valid alternative, Tactical Periodization must be properly tested and provide, in time, reasonable empirical support. On this basis, the goal of the present study was to systematically review original experimental research (qualitative, quantitative, or mixed) on Tactical Periodization in any sports or contexts. The main research question can be framed as such: 'Are there qualitative and quantitative data regarding Tactical Periodization?' 


\section{Material and methods}

\section{Eligibility and selection criteria}

This research followed the Preferred Reporting Items for Systematic Reviews and Meta-Analyses (PRISMA) guidelines [14] and included original experimental articles testing Tactical Periodization (qualitatively and/ or quantitatively) in any sports (regardless of level or context), published in English (since most scientific publications are in this language) or Portuguese (as Tactical Periodization was originally proposed by a Portuguese author). As explained in the introduction, Tactical Periodization is distinct from periodization of tactics. Following the PRISMA guidelines, the PICOS framework was established as follows: Participants humans participating in any sports; Interventions any experimental intervention directly testing Tactical Periodization (thereby excluding any opinion articles and experiments testing other concepts); Comparisons - established between Tactical Periodization and any other planning approach (hence, excluding merely observational studies; the absence of a contrast group inhibits useful analysis, as all effects might be explained by any number of factors besides those under research); Outcomes - any outcomes derived from an application of a Tactical Periodization plan (therefore, no limitations were placed with regard to outcomes); Study design - original experimental research with at least one comparison group (either control or contrast); both qualitative and quantitative analyses were considered. Also, both published articles and articles in press were included.

\section{Information sources}

The following databases were consulted: ISI Web of Science, PubMed (including MEDLINE), SciELO, Scopus, and SPORTDiscus. No restrictions were placed with regard to publication date.

\section{Search}

The identified databases were searched in late April of 2019 and then in late September of 2019. The initial screening used Boolean operators 'and' and 'or'. The title had to include 'Tactical Periodization' (or the variant 'periodisation') 'or' 'periodização tática' (the former Portuguese form 'táctica,' with an extra 'c,' was also considered). Since the experiment was to focus directly on Tactical Periodization, not having the expression in the title made the article highly unlikely to be eligible. Also, this very specific form of periodiza- tion is largely outside the scope of mainstream periodization research. Search engines did not restrict the terms to the introduced order; therefore, as long as both words (i.e., 'tactical' and 'periodization') were included in the title, the paper would appear in a first screening. No other minor keywords were used (e.g., 'soccer,' 'elite sport') since the goal was not to restrict the search to studies on a specific sport or game level.

\section{Study selection criteria}

After the initial screening, papers were selected only when they used an experimental design contrasting Tactical Periodization with alternative approaches, and analyses could be quantitative, qualitative, or mixed. Studies were included if they respected the PICOS model, as previously defined. Studies were excluded if the full text was not available or if they did not abide by PICOS. Summing up, the inclusion criteria involved: studies with human participants of any age, sports and play levels that directly investigated the effects of Tactical Periodization in a controlled or contrasted design (i.e., having at least an alternative group for comparison); all types of outcomes were considered (quantitative, qualitative, or mixed). Summarized exclusion criteria were as follows: any opinion articles, conceptual proposals, reviews, book reviews, observational studies, experimental articles testing concepts other than Tactical Periodization.

\section{Data collection process}

First, the main author extracted the data. Another author independently repeated the process within the following week. The two searches were compared to assure the quality of the retrieval and exclusion process. The remaining authors randomly cross-checked the retrieval and exclusion processes for further consistency.

The papers were manually analysed to ensure that they actually tested Tactical Periodization and compared it with alternative protocols. Two authors conducted the review of the articles, while the remaining authors randomly cross-checked several of the articles, to ensure data quality and minimize potential errors of analysis. In all stages, there was full agreement between all the authors.

\section{Data items}

No data items were retrieved since no actual experimental study was found that would evaluate Tac- 


\section{HUMAN MOVEMENT}

J. Afonso, C. Bessa, P.T. Nikolaidis, I. Teoldo, F.M. Clemente, Tactical Periodization: a review

tical Periodization, despite the popularity of the concept. Studies on periodization of tactical aspects did emerge, but were restricted to this training factor, and thereby did not follow the principles of Tactical Periodization as detailed in the introduction. Consequently, the risk of bias in individual studies and synthesis of results could not be applied since there were no actual studies available.

\section{Ethical approval}

The conducted research is not related to either human or animal use.

\section{Results}

\section{Study selection}

A total of 20 papers appeared in the primary search process; 9 articles remained after the manual removal of duplicates, and all were screened. Unfortunately, all the 9 articles were excluded: (i) the paper by Crespo [5] presented an introduction to and synthesis of the concepts involved in Tactical Periodization, but stopped there, and no experiment was conducted; (ii) Saja [15] provided a book review; (iii) Robertson and Joyce [4] produced an original investigation, but the title was somewhat misleading, as they actually evaluated the validity of a match difficulty index for use in Super Rugby; (iv) the experiment by Aquino et al. [16] applied a periodized program to technical and tactical aspects of performance, but did not follow Tactical Periodization and the concept was not even mentioned in the entire manuscript; (v) Greboggy and Silva [3] delivered an essay on the concept, but with no actual experimentation; (vi) Tee et al. [2] proposed a Tactical Periodization approach for rugby union, but there was no actual research; (vii) the research conducted by Buchheit et al. [11] examined the reliability of fieldbased running-specific measures via GPS-embedded accelerometers (hence, Tactical Periodization was not investigated); (viii) the article by Delgado-Bordonau and Mendez-Villanueva [10] was excluded since it constituted an opinion article; and finally (ix) the article by Junior [17] was excluded because it was a narrative review of different periodized models. The study flow diagram can be observed in Figure 1.

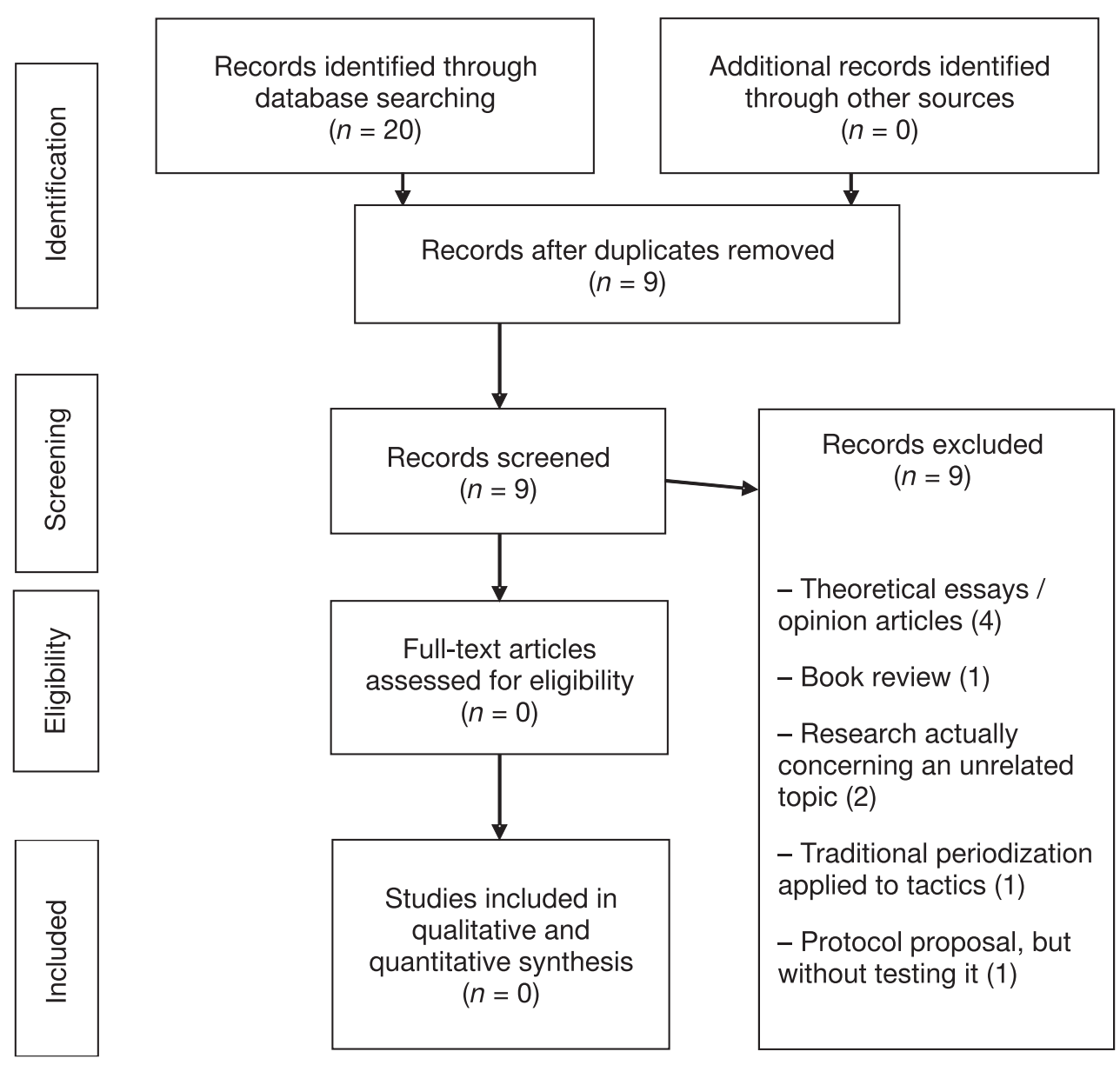

Figure 1. Flow diagram for the search process 


\section{Study characteristics}

No empirical study on Tactical Periodization (whether qualitative, quantitative, or mixed) was found in the consulted databases. Therefore, it is not possible to address study characteristics or risk of bias within and across studies, or to analyse results.

\section{Discussion}

\section{Summary of evidence}

Tactical Periodization has been increasingly recognized as an alternative paradigm to existing models of periodization. The inclusion of all major training factors (i.e., tactical, technical, physical, and psychosocial) into a coherent entirety provides a systemic approach to planning, and the greater focus on the short-term processes offers a more organic and naturally evolving take on training processes, promoting a constant interaction between plans and reality $[1,4,5]$. In line with its theoretical interest and growing popularity, it was expected that at least some level of evidence in support of Tactical Periodization would be found. However, there was no scientific evidence for (or against) Tactical Periodization, since there was a surprising lack of empirical papers that would actually investigate this concept. Despite its popularity, Tactical Periodization has not yet been the subject of scientific scrutiny and may thereby be considered an interesting theoretical proposition, but without being (yet) supported by any scientific research. This is worrisome, as its increasing popularity may suggest that this framework represents a scientifically validated concept, while, on the contrary, it has no research to support it. Therefore, the results of this systematic review constitute a serious alert to accepted practices in sports and highlight the necessity of showing what research actually exists to a wider audience. Otherwise, the field of sports sciences might become prey of opinions or pseudoscience lacking proper experimental verification.

However, the possibility that academic theses on the topic have been written (e.g., M.Sc., Ph.D.) was raised. Of course, without submitting them to journals and, as such, without subjecting them to the independent peer-review process, questions concerning the quality of these theses would arise. Still, this possibility was considered and a search was conducted on the Open Repository of the Faculty of Sport of the University of Porto (the institution where the concept of Tactical Periodization was created). This additional search re- vealed the existence of 11 academic theses ( 2 master theses, 9 monographic theses, no doctoral theses) [1828]. As with the articles published in peer-reviewed journals, none of these theses actually investigated Tactical Periodization, as they focused on interviews with coaches, narrative reviews, or unrelated research (e.g., specificity of exercises prescribed for the goalkeeper). Although these are clearly negative results, they are important in the scientific enterprise for two reasons: (i) as a demonstration that strong claims on the subject of Tactical Periodization are currently not grounded on empirical evidence; and (ii) as an example that there is a distance between opinions and science, and that discourse on the subject should perhaps be downgraded until evidence is collected. The circumstance that only 9 articles on the topic emerged (plus the 11 academic theses) and the fact that all had to be excluded since no piece of research actually conducted an experiment on Tactical Periodization are at odds with the more than 20 years of existence of Tactical Periodization, as well as with its growing popularity. This should advise practitioners and sports scientists to be cautious when applying this framework.

This work reiterates the theoretical interest in Tactical Periodization and the fact that it might be a valid alternative to current periodized models. Notwithstanding, science should not forget the implications of the burden of proof $[12,13]$, meaning that any claim should be properly tested. So far, however, there is no actual experimental research conducted on the subject and thus current statements on the idea constitute opinions and should not claim to be anything more than that. Therefore, Tactical Periodization should not be promoted as a scientifically validated approach to planning, even though its academic and practical interest and its potential as an alternative framework to other forms of periodization can be acknowledged. Overall, the absence of results should be reported to provide a properly balanced account of the science in any given field and avoid the bias toward publishing only so-called positive results, with all the scientific, societal, and economic costs associated with such a practice [29-31].

\section{Possibilities of future research}

Considering the absence of actual research on Tactical Periodization, it is necessary to understand this model as an interesting conceptual framework, but still lacking empirical validation. Descriptive observational studies conducted among teams that use such type of periodization could act as starting point, but 
ideally experimental studies contrasting Tactical Periodization with other models should be performed. Concurrently, it is important that there is an ongoing evaluation that allows comparing what was initially planned with what was actually implemented, to properly evaluate the magnitude of deviations to the plan. In addition, a dose-response relationship should be tested aiming to establish the impact of the training load and the tactical contents on some performance variables of the players and the team during a given period. Finally, comparisons between other periodized and non-periodized models should be conducted in order to understand the differences and the real influence of the models on the team's and player's performance.

\section{Limitations}

It is possible that empirical research on Tactical Periodization exists in other languages. Nonetheless, since English is the mainstream scientific language, and Portuguese is the language of origin of Tactical Periodization, searching on these two languages is likely to have provided an accurate overview of the literature on the topic. The possibility that similar concepts exist is recognized, but the goal of this work was to specifically address research on Tactical Periodization. Therefore, analysing additional or alternate models, even if similar, would fall out of the scope of this article. Finally, it is possible that the expression 'Tactical Periodization' could have emerged in abstracts or keywords, but that would likely not have provided useful data. If a study refers to a direct experiment on Tactical Periodization (as defined in the inclusion criteria), that expression will almost certainly be prominent in the title.

\section{Conclusions}

Tactical Periodization has been growing worldwide, and its adoption is increasing. Its application started in soccer, but is expanding to other sports, such as rugby and tennis. However, its growth has not been sustained by a body of scientific research, and the lack of research is surprising if compared with the popularity of the concept. For that reason, it is not yet possible to scientifically support this type of periodization. As always, the burden of proof must be applied, and this burden falls on the shoulders of the proponents [32, 33]. Furthermore, it should be brought to question why such a framework has been exhibiting such worldwide appeal despite not being supported by empirical research. Perhaps two main factors are concurring to such acritical adoption: (i) the fame and success of some soccer coaches who applied the idea may have motivated other coaches to copy such a model, even if their success was most likely a reflection of multiple factors; and (ii) the theoretical framework brings different concepts to play and represents a departure from traditional periodization approaches (as was explained in the introduction), and this novelty may be appealing to coaches who are unsatisfied with traditional periodization. All these speculations could also be the focus of future research.

\section{Disclosure statement}

No author has any financial interest or received any financial benefit from this research.

\section{Conflict of interest}

The authors state no conflict of interest.

\section{References}

1. Gomes MS. Game development in accordance with tactical periodization [in Portuguese]. Pontevedra: MC Sports; 2008.

2. Tee JC, Ashford M, Piggott D. A tactical periodization approach for rugby union. Strength Cond J. 2018;40(5): 1-13; doi: 10.1519/SSC.0000000000000390.

3. Greboggy DL, Silva WR. The tactical periodization under the justification of the neurosciences: habituation and restructuring of the decision making [in Portuguese]. Rev Bras Futsal Futebol. 2018;10(38):382-389.

4. Robertson SJ, Joyce DG. Informing in-season tactical periodisation in team sport: development of a match difficulty index for Super Rugby. J Sports Sci. 2015;33(1): 99-107; doi: 10.1080/02640414.2014.925572.

5. Crespo M. Tactical periodisation in tennis: an introduction. ITF Coach Sport Sci Rev. 2011;53(19):16-18.

6. Smith R. Cybernetics, cesarean sections and soccer's most magnificent mind. The New York Times. April 26, 2017. Available from: https://www.nytimes.com/2017/ 04/26/sports/soccer/cybernetics-cesarean-sectionsand-soccers-most-magnificent-mind.html.

7. Afonso J, Nikolaidis PT, Sousa P, Mesquita I. Is empirical research on periodization trustworthy? A comprehensive review of conceptual and methodological issues. J Sports Sci Med. 2017;16(1):27-34.

8. Tamarit Gimeno X. What is tactical periodization? Experiencing a 'game' to condition the game [in Spanish], $2^{\text {nd }}$ ed. Pontevedra: MC Sports; 2009.

9. Afonso J, Hilvoorde I, Pot N, Medeiros A, Almond L. Exercise periodization and Taleb's antifragility. In: Morouço P, Takagi H, Fernandes R (eds.), Sport science: current and future trends for performance optimization. Leiria: Escola Superior de Educação e Ciências Sociais - Instituto Politécnico de Leiria; 2018; 213-224. 
10. Delgado-Bordonau JL, Mendez-Villanueva A. Tactical periodization: Mourinho's best-kept secret? Soccer J. 2012;May/June:28-34.

11. Buchheit M, Lacome M, Cholley Y, Simpson BM. Neuromuscular responses to conditioned soccer sessions assessed via GPS-embedded accelerometers: insights into tactical periodization. Int J Sports Physiol Perform. 2018;13(5):577-583; doi: 10.1123/ijspp.2017-0045.

12. Hamilton BH, Best TM. Platelet-enriched plasma and muscle strain injuries: challenges imposed by the burden of proof. Clin J Sport Med. 2011;21(1):31-36; doi: 10.1097/JSM.0b013e318205a658.

13. Koplin JJ, Selgelid MJ. Burden of proof in bioethics. Bioethics. 2015;29(9):597-603; doi: 10.1111/bioe.12194.

14. Moher D, Liberati A, Tetzlaff J, Altman DG, PRISMA Group. Preferred Reporting Items for Systematic Reviews and Meta-Analyses: the PRISMA statement. PLoS Med. 2009;6(7):e1000097; doi: 10.1371/journal.pmed. 1000097.

15. Saja JM. Book review: Periodización Táctica vs Periodización Táctica. Vítor Frade aclara. Ed: MBF, Madrid 2013 [in Spanish]. Educ Física Ciencia. 2014;16(1):1-6.

16. Aquino RLQT, Cruz Gonçalves LG, Palucci Vieira LH, Oliveira LP, Alves GF, Pereira Santiago PR, et al. Periodization training focused on technical-tactical ability in young soccer players positively affects biochemical markers and game performance. J Strength Cond Res. 2016;30(10):2723-2732; doi: 10.1519/JSC.00000000 00001381.

17. Junior NKM. Training periodization [in Portuguese]. Educ Física Rev. 2012;6(2):1-34.

18. Gomes JS. A study of the congruence between training periodization and game models in high performance football coaches [in Portuguese]. Porto: Faculdade de Ciências do Desporto e de Educação Física da Universidade do Porto; 2004.

19. Almeida NAS. A football coach: from an apprentice to a master. A path to excellence [in Portuguese]. Porto: Faculdade de Desporto da Universidade do Porto; 2011.

20. Faria RFC. Tactical periodization: a concept-methodological imperative of higher performance in football [in Portuguese]. Porto: Faculdade de Ciências do Desporto e de Educação Física da Universidade do Porto; 1999.

21. Campos CCA. The uniqueness of a trainer's intervention as their fingerprint in the justification of tactical periodization as 'phenomenotechnique' [in Portuguese]. Porto: Faculdade de Desporto da Universidade do Porto; 2007.

22. Lopes MAD. The construction of football. The concerns of the training-habit relationship within a logic of tactical periodization / systematic modelling [in Portuguese]. Porto: Faculdade de Ciências do Desporto e de Educação Física da Universidade do Porto; 2005.

23. Ribeiro DB. 'Specific' goalkeeping training... no specificity? Football goalkeeper training methodology vs. tactical periodization [in Portuguese]. Porto: Faculdade de Ciências do Desporto e de Educação Física da Universidade do Porto; 2002.

24. Esteves FEC. Conception versus concession. Tactical periodization without operationalization [in Portuguese]. Porto: Faculdade de Ciências do Desporto e de Educação Física da Universidade do Porto; 2002.

25. Martins FCS. Tactical periodization in accordance with Vítor Frade: more than a concept, a way of being and reflecting football [in Portuguese]. Porto: Faculdade de Ciências do Desporto e de Educação Física da Unversidade do Porto; 2003.

26. Resende NMSP. Tactical periodization. A methodological concept that is a trivial consequence of the football game. A case study of a standard microcycle of a senior level football club of Porto [in Portuguese]. Porto: Faculdade de Ciências do Desporto e de Educação Física da Universidade do Porto; 2002.

27. Costa RJH. Tactical periodization. Theory and practice: what is the relationship? A case study of a standard microcycle of an under-17 football club of Porto [in Portuguese]. Porto: Faculdade de Ciências do Desporto e de Educação Física da Universidade do Porto; 2002.

28. Carvalho RPF. The operationalization of the intended way of playing (game model) and its mental representation: the role of consciousness and the contribution of neurosciences in understanding the success of tactical periodization [in Portuguese]. Porto: Faculdade de Desporto da Universidade do Porto; 2006.

29. Weintraub PG. The importance of publishing negative results. J Insect Sci. 2016;16(1):109; doi: 10.1093/ jisesa/iew092.

30. Nimpf S, Keays DA. Why (and how) we should publish negative data. EMBO Rep. 2020;21(1):e49775; doi: 10.15252/embr.201949775.

31. Mlinarić A, Horvat M, Šupak Smolčić V. Dealing with the positive publication bias: why you should really publish your negative results. Biochem Med. 2017;27(3): 030201; doi: 10.11613/BM.2017.030201.

32. Zakeri R, Van Wagoner DR, Calkins H, Wong T, Ross HM, Heist EK, et al. The burden of proof: the current state of atrial fibrillation prevention and treatment trials. Heart Rhythm. 2017;14(5):763-782; doi: 10.1016/j. hrthm.2017.01.032.

33. Pigliucci M, Boudry M. Prove it! The burden of proof game in science vs. pseudoscience disputes. Philosophia. 2014;42:487-502; doi: 10.1007/s11406-013-9500-z. 